\title{
Effects of tensile reinforcing steel ratio and Near-Surface-Mounted bar development length on the structural behavior of strengthened $\mathrm{RC}$ beams
}

\author{
Hesham EL-Emam ${ }^{\mathrm{a}}$ (D), Alaaeldin El-Sisi ${ }^{\mathrm{a}, \mathrm{b}}$ (D), Mohamed Bneni ${ }^{\mathrm{a}, \mathrm{c*}}$ (D), Seleem S. E. Ahmad ${ }^{\mathrm{a}}$ (D), \\ Hossam El-Din M. Sallama ${ }^{\text {iD }}$ \\ a Faculty of Engineering, Zagazig University, Zagazig 44519, Egypt. E-mails: elemamh@yahoo.com, elsisiae@missouri.edu, \\ mohamedbneni@yahoo.com, seleemahmad62@yahoo.com,hem_sallam@yahoo.com \\ ${ }^{b}$ Department of Civil and Environmental Engineering, University of Missouri, Columbia, MO 65211-2200, United States \\ ${ }^{\mathrm{c}}$ Faculty of Engineering, University of Zawai, Zawai 16418, Libya \\ * Corresponding author
}

https://doi.org/10.1590/1679-78255836

\begin{abstract}
The use of near-surface mounted (NSM) Glass fiber reinforced polymer (GFRP) bars is one of the most popular and effective techniques for strengthening reinforced concrete (RC) beams. This paper presents an experimental research program to study the flexural strengthening of RC beams comparing two areas of bottom tensile reinforcing steel and three development lengths of NSM GFRP bars. The beam test results indicated that the beam flexural strength increased up to $110 \%$ and $58 \%$ for the cases of low and high tensile reinforcing steel ratios, respectively. The effect of the tensile reinforcing steel area on the critical value of the development length of NSM GFRP bars was also investigated. It was found that decreasing the axial stiffness ratio, reduced the strengthening efficiency and the critical development length of the NSM GFRP bars. Finally, a 3D Finite Element (FE) model using ANSYS was constructed and was validated using the experimental results. Good agreement was seen between experimental and FE model results.
\end{abstract}

\section{Keywords}

NSM, GFRP rods, flexural strengthening, critical development length, FE analysis

\section{Graphical Abstract}

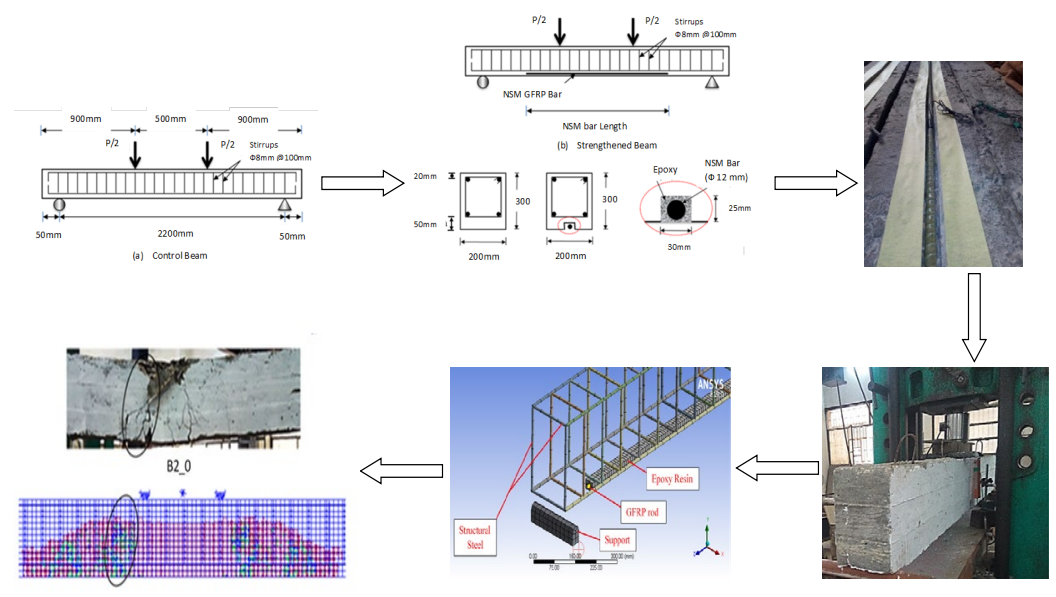




\section{INTRODUCTION}

Near-surface mounted (NSM) and externally bonded reinforcement techniques are among the most popular methods to improve the strength of reinforced concrete (RC) beams. However, externally bonded reinforcement suffers from a high possibility of premature failure and is exposed to thermal, environmental, and mechanical damage. Therefore, the NSM strengthening technique offers an effective substitute (ACl, 2012, 2017; Barros et al., 2007; Barros and Kotynia, 2008; Akbarzadeh and Maghsoudi, 2010; Zhou et al., 2013). Recently, many different strengthening techniques have been explored in an attempt to improve the service life of concrete structures (Sharaky et al., 2015, 2017, 2018, 2020; EL-Emam et al., 2020; Sallam et al., 2004; Brena et al., 2003; Tang et al., 2006; Nguyen et al., 2001; Hawileh et al., 2014). Several studies have been carried out using fiber-reinforced polymer (FRP) materials to explore the flexural behavior of RC beams strengthened with NSM (Soliman et al., 2010; El-Hacha and Rizkalla, 2004; El-Hacha and Gaafar, 2011; De Lorenzis et al., 2000; Badawi and Soudki, 2009; Al-Mahmoud et al., 2009). High strength, light weight, corrosion resistance, and high durability are some of the advantages of FRP reinforcement. However, FRP reinforcements are materials having low ductility (Rahal and Rumaih, 2011; Kalupahana, 2009; Husain et al., 2015; Sharaky et al., 2013). Furthermore, earlier investigations found that NSM FRP strengthening cannot be extended to the maximum tensile strength, due to the premature failure from FRP debonding and/or concrete splitting modes of failure (Nguyen et al., 2001; Mukhopadhyaya and Swamy, 2001; Barros et al., 2006).

Studies have investigated the effects of mechanical properties, FRP bar cross-section area, and the type of adhesive epoxy on the beam flexural strength and the load-carrying capacity of strengthened beams using the NSM technique (Sharaky et al. 2013, 2014; Reda et al., 2016; Shabana et al., 2018). It has been found that the maximum load-carrying capacity of the beams strengthened with NSM FRP is significantly affected by the stiffness the FRP bars used.

This paper describes an experimental research program to study the flexural strengthening of RC beams with two different areas of bottom tensile reinforcing steel and three different NSM glass FRP (GFRP) development lengths. The effects of the area of the tensile reinforcing steel on the efficiency of the strengthening by NSM GFRP bars and on the bars' critical development length are also experimentally investigated. Finally, a numerical model using the ANSYS 3D-FE analysis software was developed to investigate the flexural behavior of NSM-GFRP strengthened beams.

\section{EXPERIMENTAL PROGRAM}

In this section, the experimental study is described, and the testing matrix, test setup, and data collection instruments are presented.

\subsection{Test matrix}

A total of eight $\mathrm{RC}$ rectangular beam specimens were tested. The beams were divided into two series. The first series (B1) consisted of four beams: the control beam (B1_0) had no strengthening, and the remaining beams were strengthened using GFRP bars of different lengths. The second series (B2) also consisted of four beams: the control beam (B2_0) had no strengthening, and the remaining beams were strengthened using GFRP bars with different lengths and different areas of the tensile reinforcing steel bars. Table 1 provides the configuration of the tested RC beams in the experimental study.

\subsection{Specimen configuration}

Eight RC beams were tested after 28 days from casting using four-point bending and were designed as under reinforced beams to initiate the flexure tension failure, according to the $\mathrm{ACl}$ code. All beams have a total length of $2300 \mathrm{~mm}$ and a rectangular cross-section of $200 \mathrm{~mm} \times 300 \mathrm{~mm}$. The longitudinal reinforcement consists of four steel bars: two in tension and two in compression.

Table 1 Configuration of the tested RC beams.

\begin{tabular}{|c|c|c|}
\hline Beam ID & NSM bar length & Bottom reinforcement \\
\hline B1_0 (Control) & ------ & \multirow{4}{*}{$\rho_{\min } 2 \Phi 10 \mathrm{~mm}$} \\
\hline B1_1 $1_{(0.25 L)}$ & $550 \mathrm{~mm}$ & \\
\hline B1_2 $(0.5 \mathrm{~L})$ & $1150 \mathrm{~mm}$ & \\
\hline B1_3(0.8L) & $1800 \mathrm{~mm}$ & \\
\hline B2_0(Control) & ------ & \multirow{4}{*}{$(50 \%) \rho_{\max } 2 \Phi 16 \mathrm{~mm}$} \\
\hline B2__1 (0.25L) & $550 \mathrm{~mm}$ & \\
\hline B2_2 (0.5L) & $1150 \mathrm{~mm}$ & \\
\hline B2_3(0.8L) & $1800 \mathrm{~mm}$ & \\
\hline
\end{tabular}


Steel stirrups of $8 \mathrm{~mm}$ diameter were spaced every $100 \mathrm{~mm}$ along the beam span. After casting the RC beams, grooves of $30 \mathrm{~mm} \times 25 \mathrm{~mm}$ were cut into the bottom to establish the NSM GFRP bars, as shown in Figure 1 .

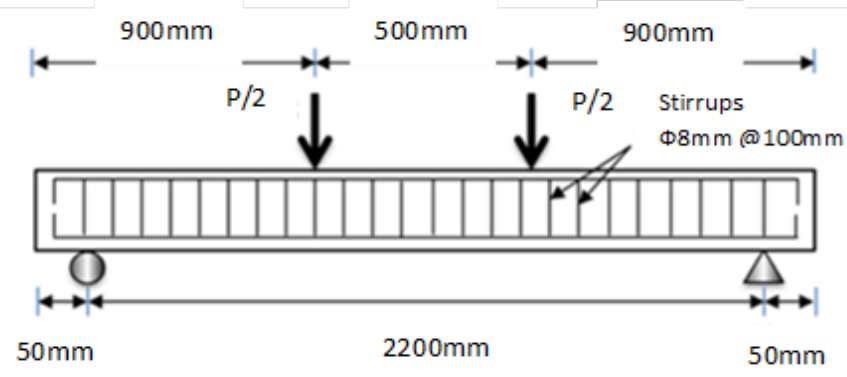

(a) Control Beam

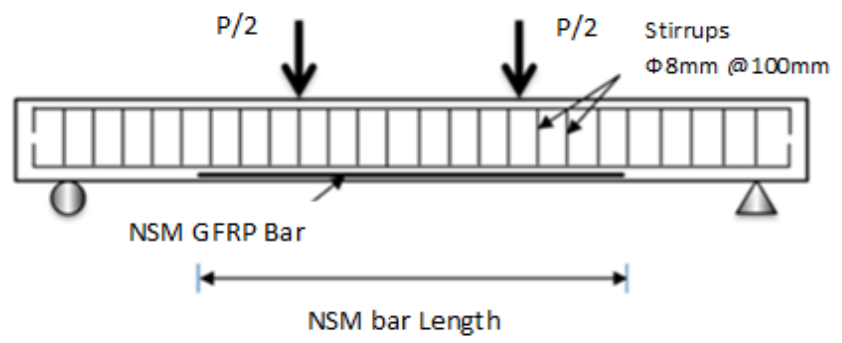

(b) Strengthened Beam
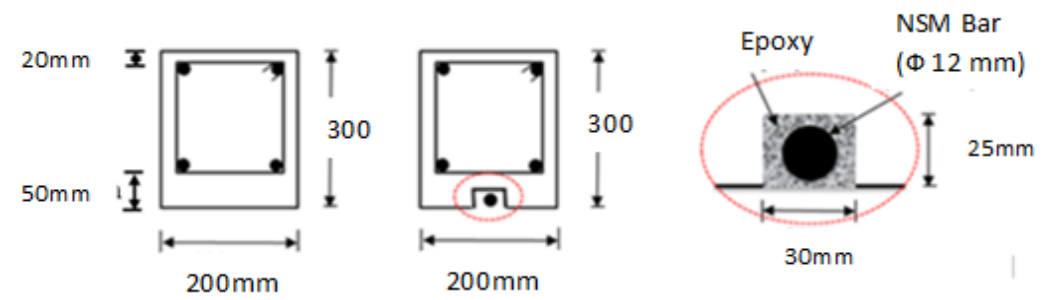

Figure 1: Specimen design details.

\subsection{Material properties}

All the beams were cast using normal concrete. Crushed dolomite with 20-mm maximum aggregate size was used as coarse aggregate, and natural sand was used as fine aggregate. The cement was hydrated using fresh tap water during the casting and curing of the beams, cubes, and cylinders. Based on tests of three $150 \mathrm{~mm} \times 150 \mathrm{~mm} \times 150 \mathrm{~mm}$ concrete cubes, the 28-day average compressive strength of the concrete was $35 \mathrm{MPa}$, while the splitting tensile strength was $2.95 \mathrm{MPa}$ based on tests of three $150 \mathrm{~mm} \times 300 \mathrm{~mm}$ concrete cylinders. For the $\phi 8$ steel bar and the $\phi 10$ and $\phi 16 \mathrm{~mm}$ steel bars, the yield and ultimate strength were $480 \mathrm{MPa}$ and $590 \mathrm{MPa}$, respectively. The modulus of elasticity for all bars was $200 \mathrm{GPa}$. MasterBraceSAT 4500 (BASF), an epoxy adhesive, was used to bond the GFRP bars to the concrete substrate. The GFRP bars were from the Haining Anjie Composite Material Company in China. The density, yield strength, ultimate tensile strength, and modulus of elasticity of the GFRP bars were $2.1 \mathrm{~g} / \mathrm{cm}^{3}, 750 \mathrm{MPa}, 870 \mathrm{MPa}$, and $40 \mathrm{GPa}$, respectively.

\subsection{Strengthening procedures}

The NSM technique involves cutting a groove into the concrete cover of the RC beams with dimensions specified in Figure 1. To simulate field application cases, the grooves were cut at the tension face in the longitudinal direction 28 days after the casting of the beams. The grooves were partially filled with epoxy adhesive, and the bars were then placed and pressed slightly into the adhesive. The rest of each groove was then filled with adhesive, and the surface was leveled, as shown in Figure 2. The beams were then left for more than one week to ensure that full adhesive strength had been achieved. 


\subsection{Test setup}

The beam test setup is shown in Figure 3. A linear variable differential transformer (LVDT) was used to measure the mid-span vertical deflection. For each beam, two strain gauges were mounted to the middle of the NSM GFRP bars and the tension reinforcing steel. A 1000-KN universal testing machine was used to test all beams in four-point bending.
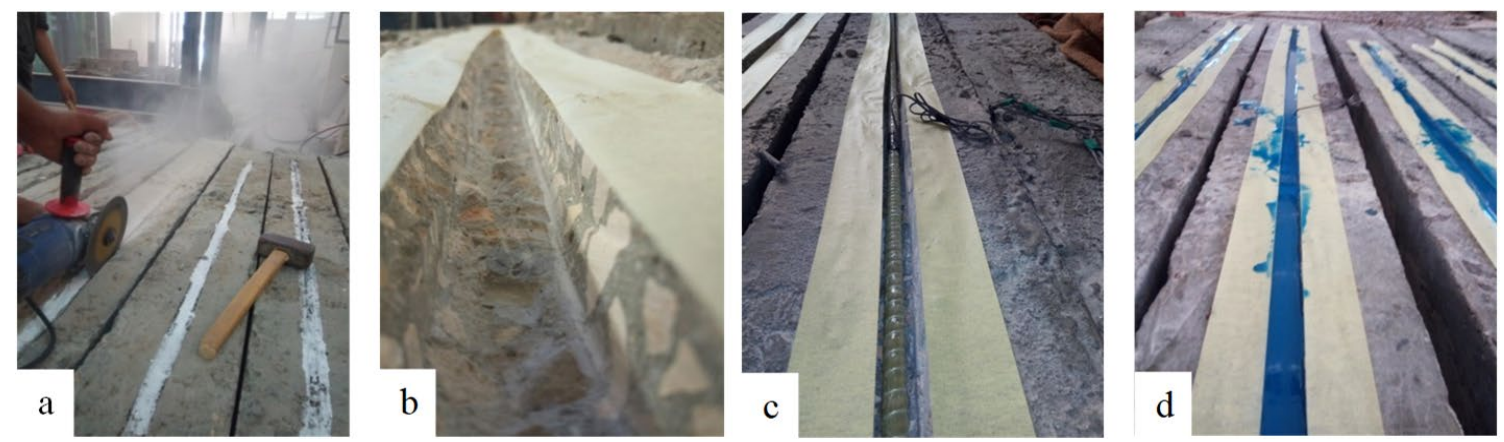

Figure 2: Cutting grooves and Installation of GFRP bars.

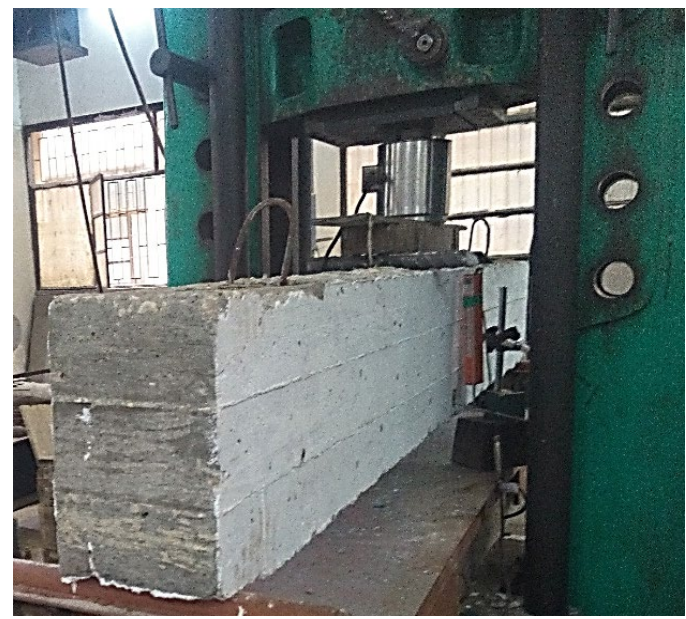

Figure 3: Set up and instrumentation.

\section{RESULTS AND DISCUSSION}

In this section, the results of the experiments and numerical models are presented and discussed.

\subsection{Mode of failure of strengthened beams}

Figure 4 presents the modes of failure for all the tested beams. As designed, the control beams B1_0 and B2_0 failed in a flexural mode, which is a yielding of the reinforcing steel followed by crushing of the concrete. For beams B1_1 and B2_1, a crack started at the critical section (the end of the GFRP rod), which is near the constant moment region and then propagated toward the strengthened section. The cracks spread horizontally at the reinforcing steel level causing concrete cover separation in the case of beam B2_1 (2Ф16 mm bottom reinforcing steel). However, the crack inclined slightly toward the nearest loading point in beam B1_1 (2Ф10 $\mathrm{mm}$ bottom reinforcing steel), creating a flexural shear mode of failure. In the case of beam B2_1, the concrete cover separation occurred, whereas the maximum bond stress was achieved. The bond stress depends on the radial stress applied by the bar on the adjacent epoxy and is neutralized by concrete cover tensile stresses).

Increasing the GFRP development length enhanced the beam's mode of failure. For beams B1_2 and B1_3, the cracks started at the end of the GFRP rod and at the maximum bending moment region. However, the crack at the rod end grew faster than the others and inclined steeply toward the location of the point of loading. These beams finally failed after GFRP rod debonding. In beam B2_2, the failure mode was flexural failure followed by GFRP rod debonding; for beam B2_3, the failure mode was flexural failure followed by concrete cover separation and GFRP rod debonding. 


\subsection{Load-deflection curve and strengthening efficiency}

Figure 5 shows the load mid-span deflection curves of the tested beams. The beam response shows a trilinear behavior defined by three regions: the elastic region with concrete cracking, the region of steel yielding with continuous concrete crack growth, and the region beyond yielding up to the point failure (concrete crushing due to compression stress), i.e., typical failure of under-reinforced beams. In the first region, the NSM GFRP bar did not contribute to beam stiffness. However, the NSM GFRP bar significantly increased the beam stiffness and strength in the second region. The yield loads for the strengthened beams B1_1, B1_2, and B1_3, with tensile reinforcement $2 \Phi 10$ $\mathrm{mm}$, were increased by $39 \%, 82 \%$, and $139 \%$, respectively, over the control beam (B1_0). For the beams with tensile reinforcement $2 \Phi 16 \mathrm{~mm}$, the yield load increased by $27 \%, 70 \%$, and $78 \%$ for beams B2_1, B2_2, and B2_3, respectively, over the control beam (B2_0).
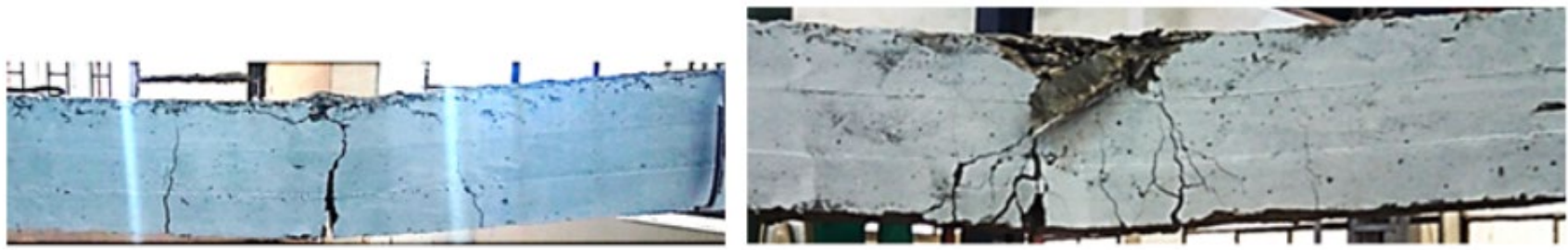

B1_0
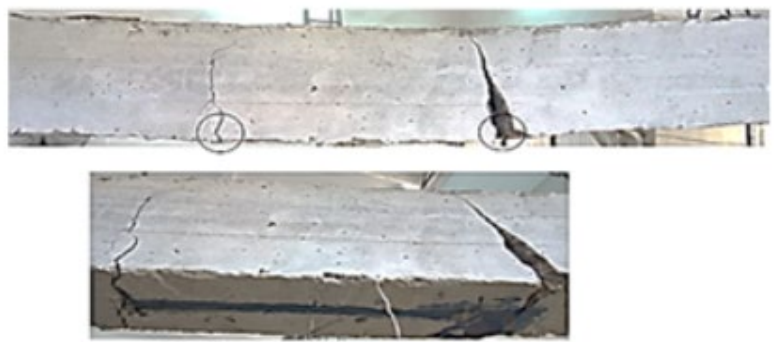

B1_1

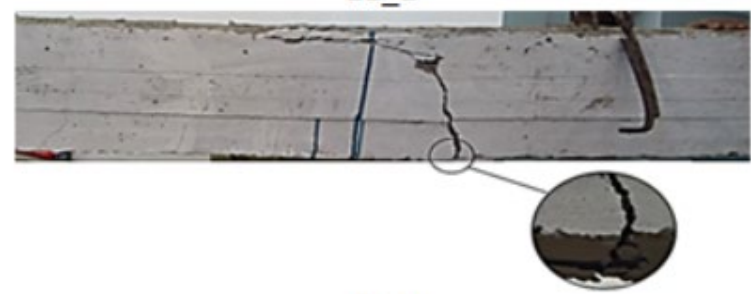

B1_2

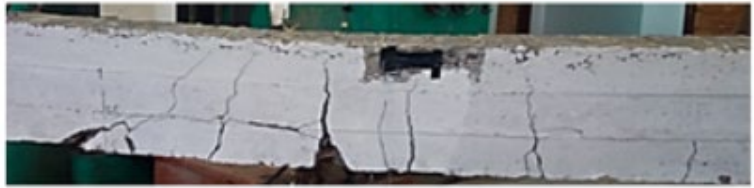

B1_3

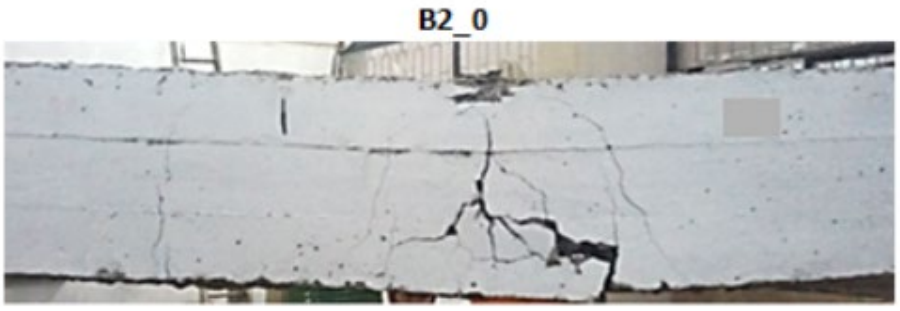

B2 1

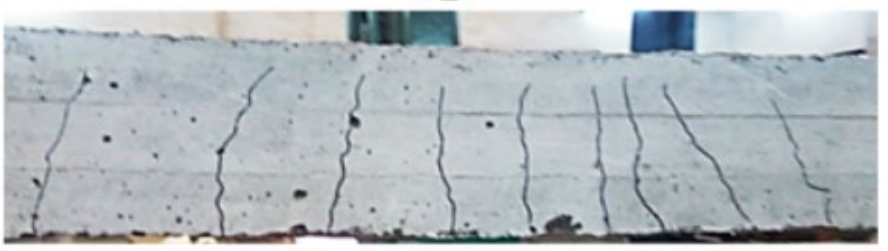

B2 2

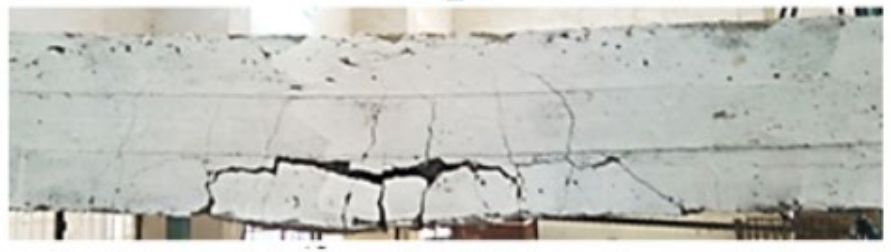

B2_3

Figure 4: Failure modes of the tested beams.

In the third of the trilinear regions, after the yielding of the tensile steel and the low elastic modulus for GFRP bars, the overall beam stiffness was decreased, as shown in Figure 5. However, the ultimate load-carrying capacity of the strengthened beams was improved by increasing the NSM GFRP bar development length. Beam B1_1, strengthened with $0.25 \mathrm{~L}$ GFRP bar length, failed at a load of $56 \mathrm{kN}$. Increasing the GFRP bar length to $0.5 \mathrm{~L}$ and $0.8 \mathrm{~L}$ for beams B1_2 and B1_3 increased the ultimate loads to $72 \mathrm{kN}$ and $97 \mathrm{kN}$, respectively. In the second series, beam B2_1 failed at $116 \mathrm{kN}$. Beams B2_2 and B2_3, with greater bar lengths, both had an ultimate load value of around $150 \mathrm{kN}$, as shown in Figure 5. It could be concluded that strengthening efficiency was affected by the tensile reinforcing steel ratio. 

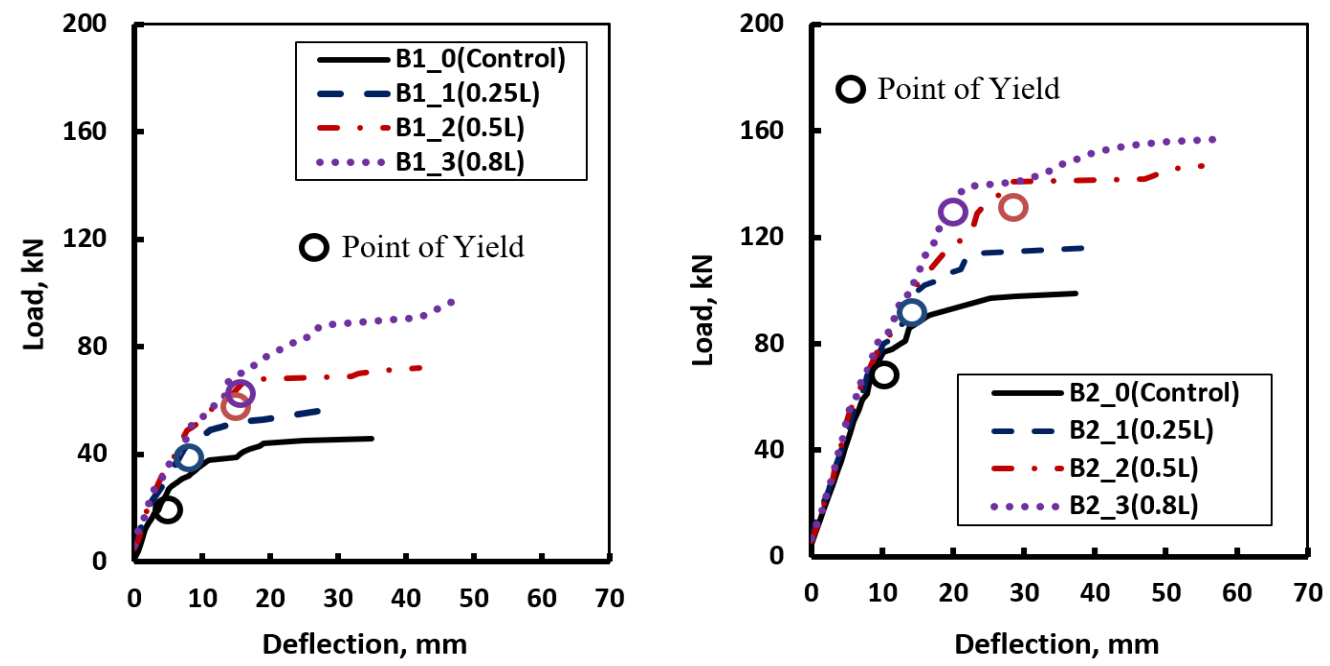

Figure 5: Load-deflection curves for the tested beams.

\subsection{Effect of tensile steel reinforcement on the NSM GFRP strengthening efficiency}

Based on the previous discussion and the results in Figure 6, the bottom tensile reinforcing steel ratio governed the strengthening efficiency of the NSM GFRP bars. As shown in Figure 6, the ultimate loads in the first beams series (B1), with tensile reinforcing steel $2 \Phi 10 \mathrm{~mm}$, were significantly improved by increasing the GFRP rod length. In the second beams series (B2), however, increasing the GFRP rod length beyond $0.5 \mathrm{~L}$ produced no significant improvement in ultimate load. Therefore, the critical development length of the NSM GFRP bar was affected by the bottom tensile reinforcing steel ratio. This might be due to the axial stiffness ratio $\left(E_{f} A_{f} / E_{s} A_{s}\right)$, which is the relation between GFRP axial stiffness $\left(E_{f} A_{f}\right)$ and the tensile reinforcing steel axial stiffness $\left(E_{s} A_{s}\right)$. In this ratio, $E_{f}$ and $A_{f}$ are the GFRP elastic modulus and cross-section area, respectively, and $E_{s}$ and $A_{s}$ are the tensile reinforcing steel bar elastic modulus and cross-section area, respectively. Thus, the stiffness ratios for the first (B1) and second (B2) series of beams were $28.8 \%$ and $11.25 \%$, respectively. It can be concluded that decreasing the stiffness ratio reduces the strengthening efficiency and the critical development length of the NSM GFRP strengthening bars, as shown in Figure 6.

\subsection{Strain distribution}

The load versus strain values at the midpoints of the NSM GFRP bars are shown in Figure 7. The load-strain curve of the NSM GFRP bar follows the same trend as previously shown for a load-deflection curve. It shows a trilinear behavior defined by three stages: elastic region of concrete cracking, region of steel yielding, and region beyond yielding up to failure.

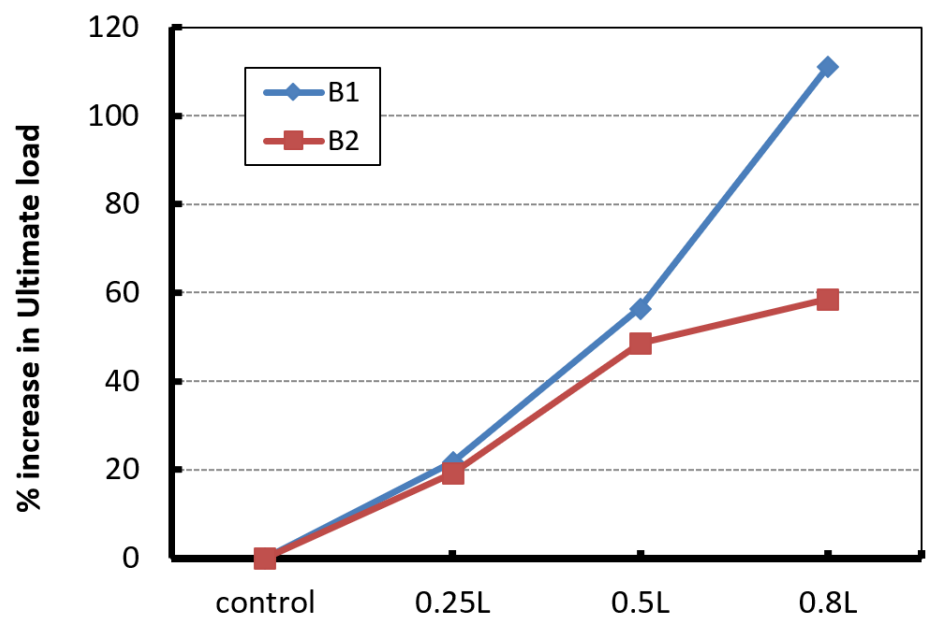

Figure 6: Percent increase in the strengthened beams' ultimate load compared to the control beams. 

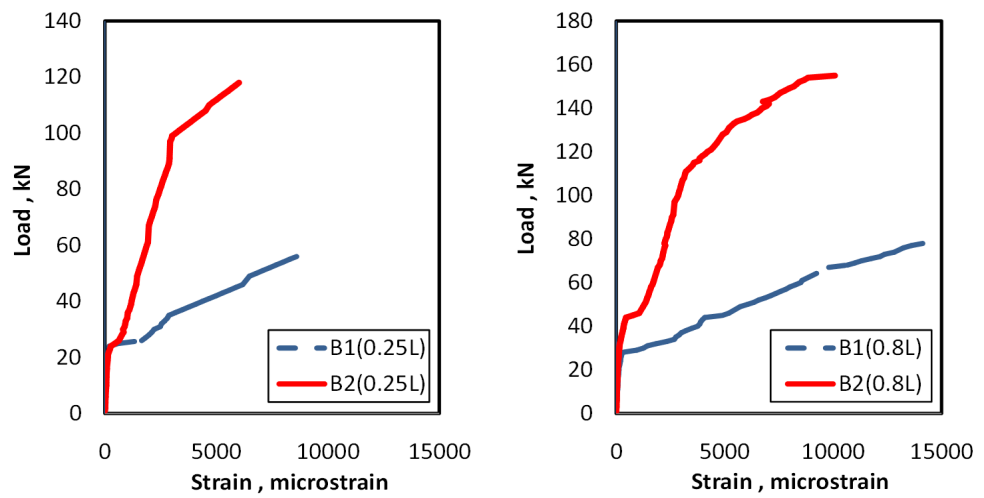

Figure 7: Strain in the middle of the NSM GFRP bar.

\subsection{Finite element modeling and comparison}

The FE modeling was used to simulate and analyze the beams. The behaviors of concrete, tensile steel reinforcement, GFRP, and the epoxy adhesive were simulated using suitable element types and material constitutive models. The concrete and the adhesive were modeled using element SOLID65 (an eight-node element). This element has the ability to crack under tension and crush under compression and is defined by eight nodes with three degrees of freedom in the $x, y$, and $z$ directions. Element LINK180 (a 3D two-node structural bar element) was used to simulate the tensile steel reinforcement and GFRP bars. The element is a uniaxial tension-compression element with three degrees of freedom at each node, with translations in the nodal $x, y$, and $z$ directions. Additionally, element SOLID185 (an eight-node solid element) was used to model the loading and supporting plates. This element is defined by eight nodes with three degrees of freedom at each node and translations in nodal $x, y$, and $z$ directions, and it has the ability to incorporate nonlinearity and large deformations, as shown in Figure 8 (ANSYS I., 2017).

\subsubsection{Failure and yield criteria for concrete and steel}

SOLID65 (concrete) is able to predict both smeared cracking and crushing modes of failure for concrete materials (El-Sisi et al., 2019). The two input strength parameters - that is, ultimate uniaxial tensile and compressive strengths-are needed to define a failure surface for the concrete. In a concrete element, cracking occurs when the principal tensile stress in any direction lies outside the failure surface (ANSYS I., 2017). In LINK180 (steel), von Mises is used as the yield criterion: that is, a stress state reaches the yield state when the von Mises stress $\sigma_{\mathrm{e}}$ is equal to the current uniaxial yield strength $\sigma_{\mathrm{y}}$.

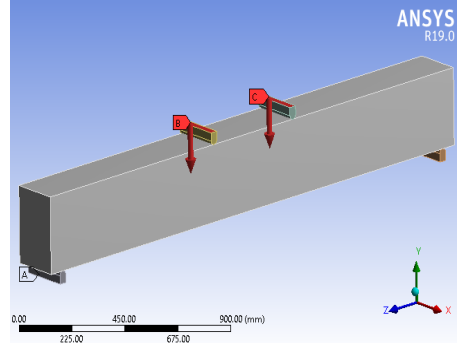

(a)

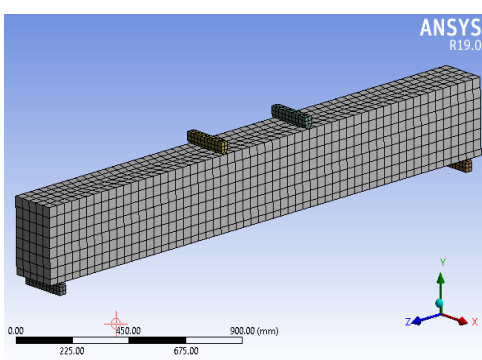

(b)

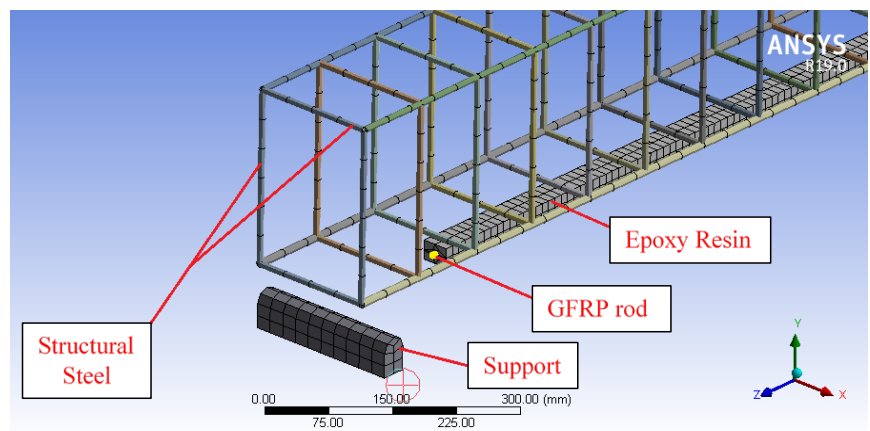

(c)

Figure 8: The numerical model: (a) RC beam, (b) meshing, and (c) structural model. 
Figures 9 and 10 compare the experimental and numerical results of the control and the NSM GFRP-strengthened beams. The comparisons show a good agreement between the FE modeling and experimental results. The ultimate loads obtained from the FE models are almost equal to the ultimate loads measured in the experimental work. Figures 11 and 12 reproduce the crack patterns of the tested beams at the ultimate load. It can be concluded that the developed FE models are valid and can capture the behavior of the RC beams strengthened with NSM GFRP bars.
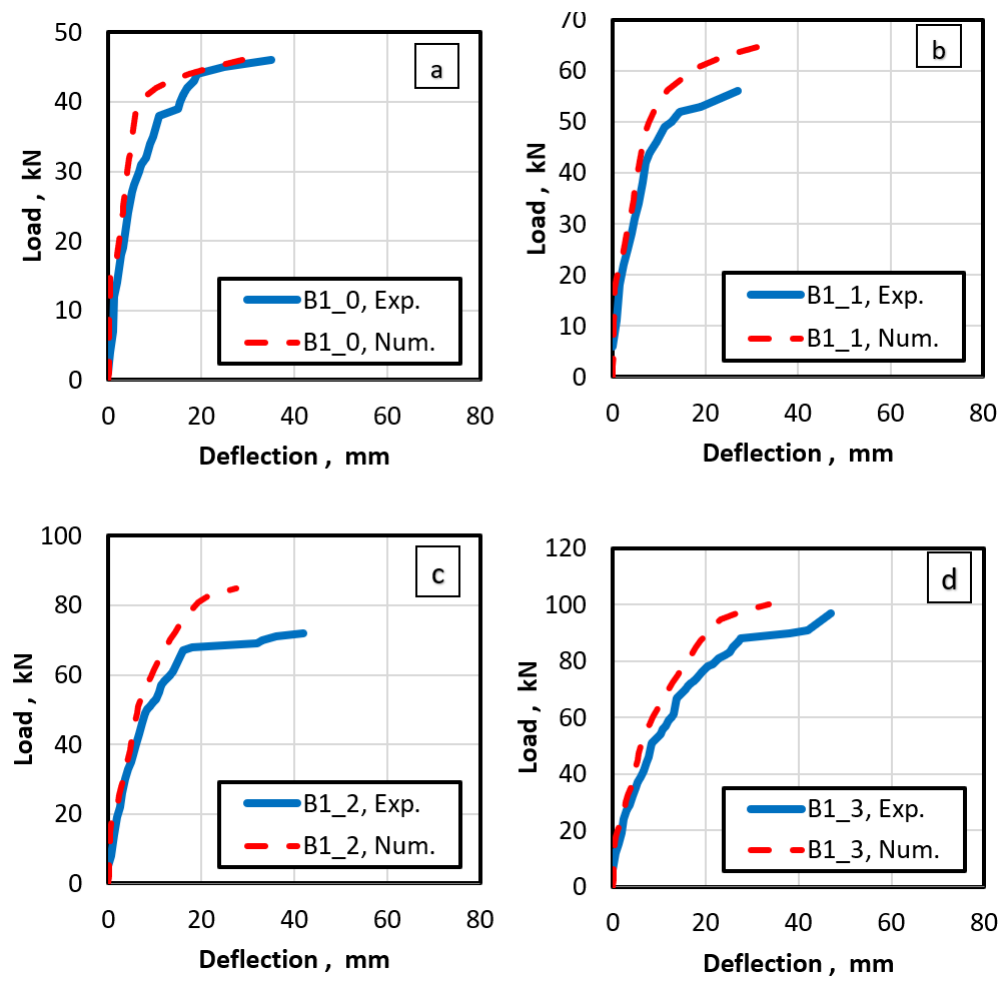

Figure 9: Comparison between experimental and FE results of the B1 beams.
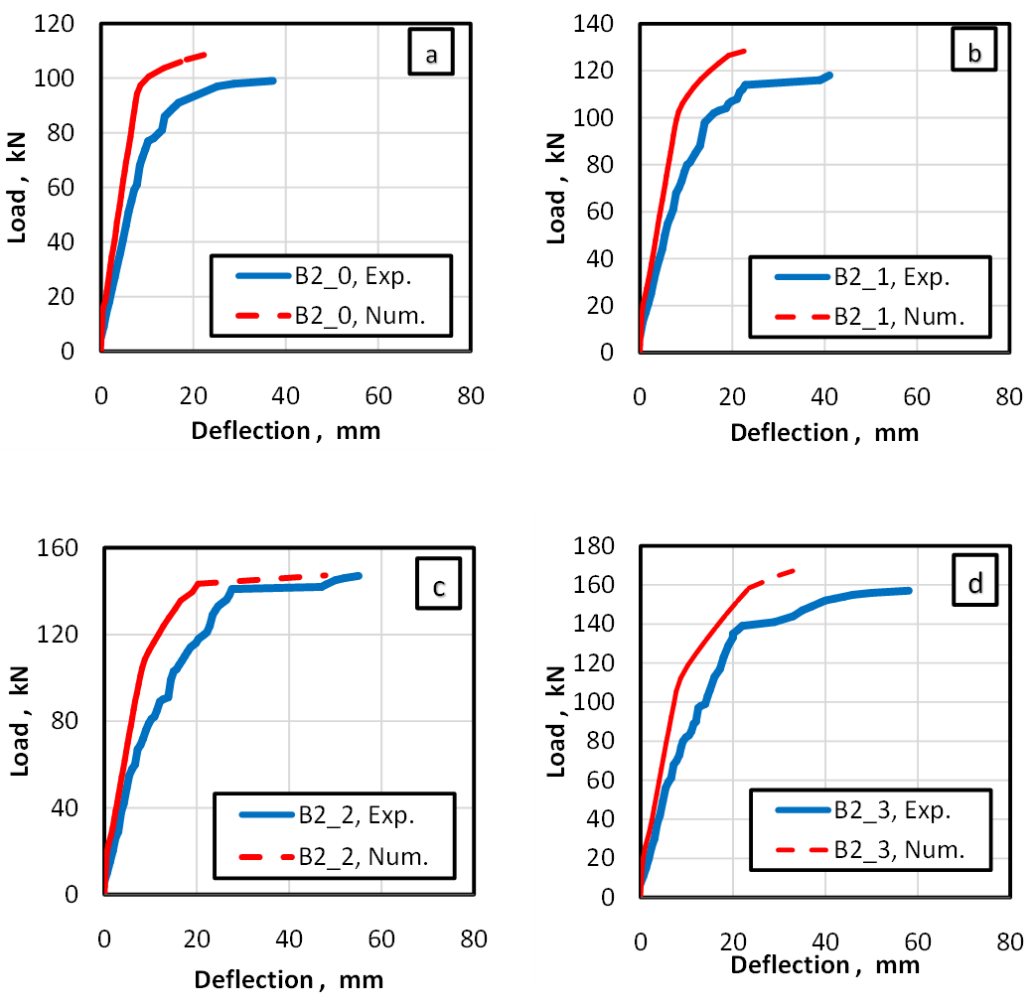

Figure 10: Comparison between experimental and FE results of the B2 beams. 


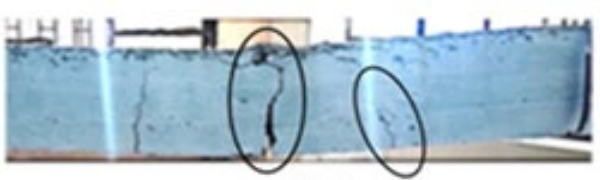

B1_0

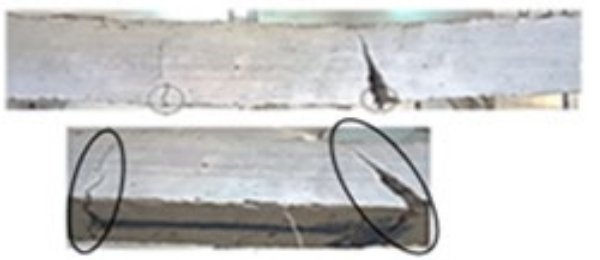

B1_1
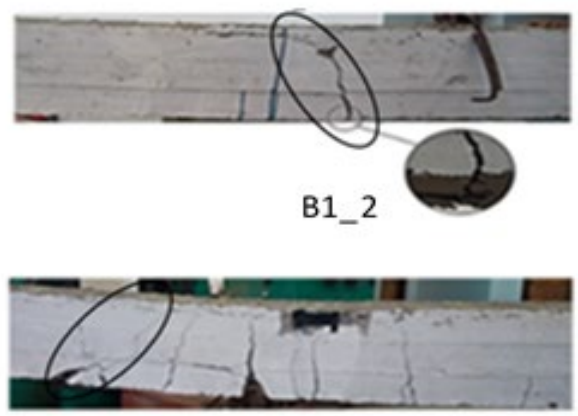

B1_3
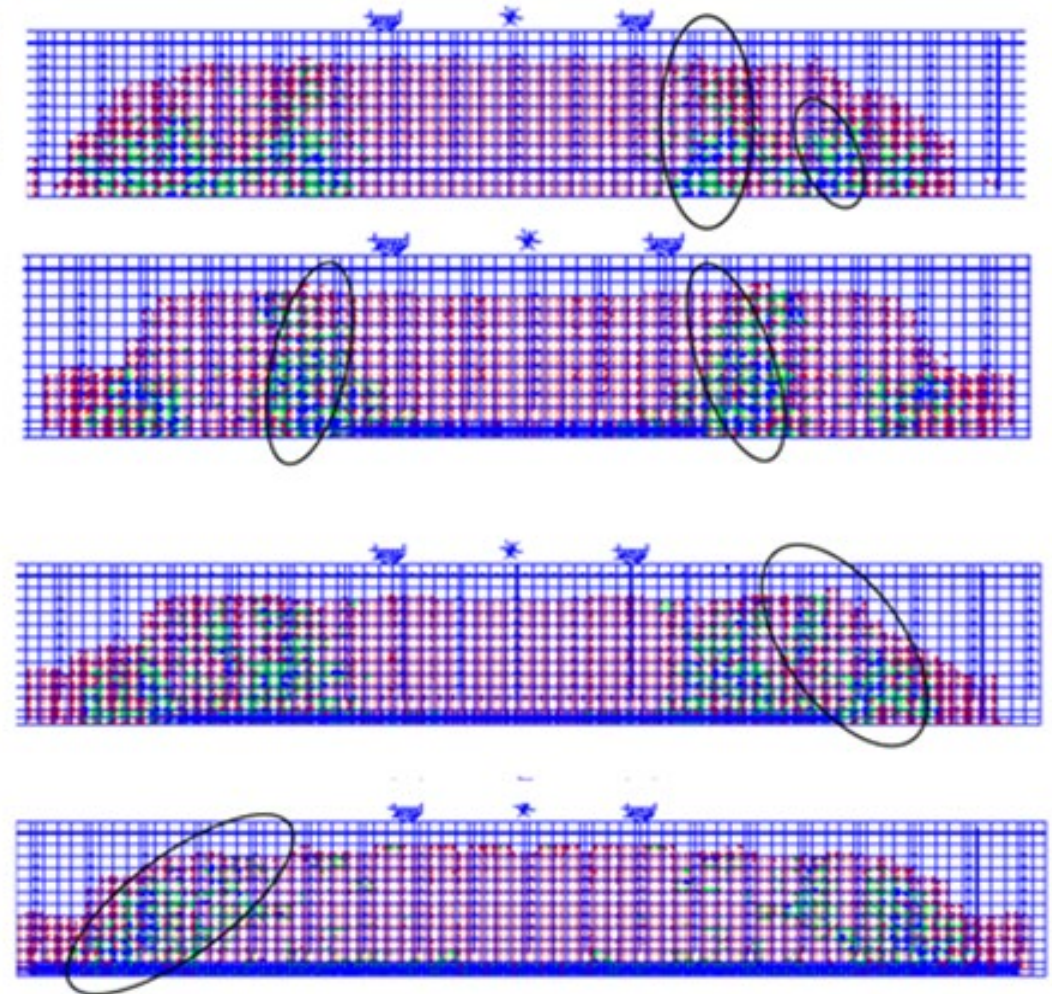

Figure 11: Predicted crack pattern and mode of failure of the B1 beams.

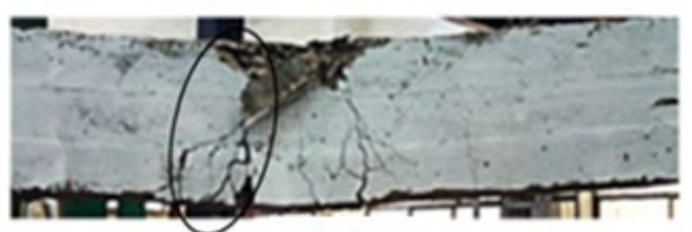

B2_0

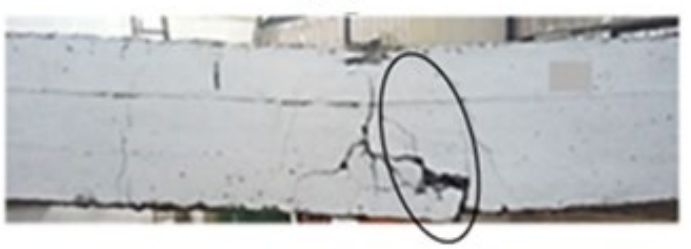

B2_1

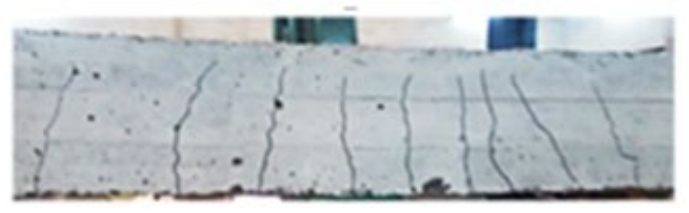

B2_2
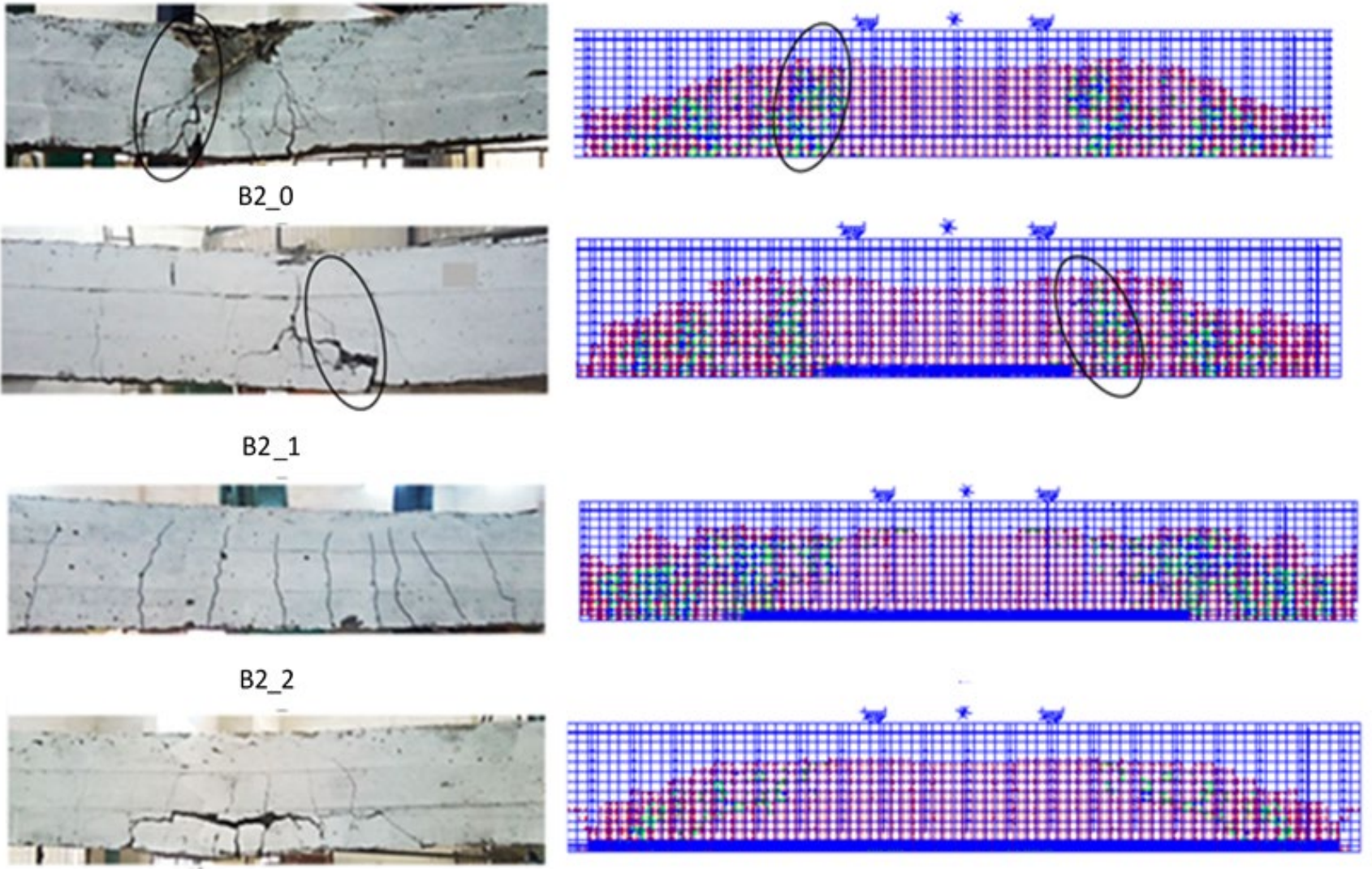

B2_3

Figure 12: Predicted crack pattern and mode of failure of the B2 beams. 


\section{CONCLUSION}

An experimental and numerical investigation was carried out to study the effects of tensile reinforcing steel ratio and the development length of the NSM GFRP bar on the efficiency of the strengthened RC beams. The experimental and numerical results indicate that increasing the GFRP development length changes a beam's mode of failure, giving it greater capacity and more ductility. The load-carrying capacity of a strengthened beam is improved by increasing the NSM GFRP bar development length. The bottom tensile reinforcing steel governs the efficiency of the strengthening by NSM GFRP bars. Decreasing the axial stiffness ratio reduces the strengthening efficiency and the critical development length of the NSM GFRP strengthening bars. Tests demonstrated that beam flexural strength increased up to $110 \%$ and $58 \%$ for low-tensile and high-tensile reinforcing steel, respectively. The developed FE models were validated using the experimental results and found to be in good agreement with those results.

Author's Contributions: All authors made the same contributions.

Editor: Pablo Andrés Muñoz Rojas.

\section{References}

ACl, 440.2 R-17 (2017): Guide for the design and construction of externally bonded FRP systems for strengthening concrete structures. Farmington Hills, Michigan, American Concrete Institute.

ACl, 440.3R-12 (2012). Guide for Test Methods for Fiber Reinforced Polymers (FRP) for Reinforcing and Strengthening Concrete Structures, ACl Committee 440, American Concrete Institute, Farmington Hills, Mich.

ANSYS I. (2017) ANSYS Release 18.1 Documentation.

Akbarzadeh, H. and Maghsoudi, A. (2010). Experimental and analytical investigation of reinforced high strength concrete continuous beams strengthened with fiber reinforced polymer, Materials \& Design, 31(3): pp. 1130-1147.

Al-Mahmoud, F., Castel, A., Francois, R. and Tourneur, C.(2009). Strengthening of RC members with near-surface mounted CFRP rods, Composite Structures, 91(2): pp. 138-147. http://dx.doi.org/10.1016/j.compstruct.2009.04.040

Badawi, M. and Soudki, K. (2009). Flexural strengthening of RC beams with prestressed NSM CFRP rods-Experimental and analytical investigation, Construction and Building Materials, 23(10): pp. 3292-3300.

http://dx.doi.org/10.1016/j.conbuildmat.2009.03.005

Barros, J.A., Dias, S.J. and Lima, J.L. (2007). Efficacy of CFRP-based techniques for the flexural and shear strengthening of concrete beams, Cement and Concrete Composites, 2007. 29(3): pp. 203-217.

http://dx.doi.org/10.1016/j.cemconcomp.09.001

Barros JAO, Ferreira DRM, Fortes AS and Dias SJE, (2006). Assessing the effectiveness of embedding CFRP laminates in the near surface for structural strengthening, Construction and Building Materials, 20:478-91.

Barros, J.A. and Kotynia, R. (2008). Possibilities and challenges of NSM for the flexural strengthening of RC structures.

Brena, S.F., Bramblett, R.M., Wood, S.L., and Kreger, M.E. (2003). Increasing flexural capacity of reinforced concrete beams using carbon fiber reinforced polymer composites, ACl Structural Journal, 100(1).

De Lorenzis, L., Nanni,A. and La Tegola, A. (2000).Strengthening of reinforced concrete structures with near surface mounted FRP rods. in International Meeting on Composite Materials, PLAST 2000, Proceedings, Advancing with Composites.

El-Hacha, R. and Rizkalla, S.H. (2004). Near-surface-mounted fiber-reinforced polymer reinforcements for flexural strengthening of concrete structures, ACI Structural Journal, 101(5).

El-Hacha, R. and Gaafar, M. (2011) .Flexural strengthening of reinforced concrete beams using prestressed near-surfacemounted CFRP bars, PCl journal, 56(4): pp. 134-151.

EL-Emam, H., EL-Sisi, A., Reda, R., Seleem, M. and Bneni, M. (2020). Effect of concrete cover thickness and main reinforcement ratio on flexural behavior of RC beams strengthened by NSM-GFRP bars, Fratturaed Integrità Strutturale, 52, pp:197-210. 
El-Sisi, A., Saucier, A., Salim, A. and Hoemann, J., (2019), Experimental and Numerical Evaluation of Reinforced Concrete Walls Retrofit Systems for Blast Mitigation, Journal of Performance of Constructed Facilities 33(2).

https://doi.org/10.1061/(ASCE)CF.1943-5509.0001265

Husain, M., Fawzy, K. and Nasr, M., (2015). Strengthening of Reinforced Concrete Beams using Near-Surface Mounted FRP, International Journal of Engineering Science and Innovative Technology (IJESIT), 4(5): pp.59-73.

Hawileh, R.A., Rasheed, H.A., Abdalla, J.A., and Al-Tamimi, A.K. (2014). Behavior of reinforced concrete beams strengthened with externally bonded hybrid fiber reinforced polymer systems, Materials \& Design, 53: pp. 972-982. http://dx.doi.org/10.1016/j.matdes.2013.07.087

Kalupahana, K. (2009). Anchorage and Bond Behaviour of Near Surface Mounted Fiber Reinforced Polymer Bars" PhD thesis, University of Bath, UK.

Mukhopadhyaya P, Swamy R.N. (2001). Interface shear stress: a new design criterion for plate debonding. Composite Structures, 5:35-43.

Nguyen, D.M., Chan, T.K. and Cheong, H.K. (2001).Brittle failure and bond development length of CFRP concrete beams, Journal of Composites for Construction, 5(1): pp. 12-17. http://dx.doi.org/10.1061/(ASCE)1090-0268(2001)5:1(12)

Rahal, K.N. and Rumaih, H.A. (2011). Tests on reinforced concrete beams strengthened in shear using near surface mounted CFRP and steel bars. Engineering Structures, 33(1); pp: 53-62. http://dx.doi.org/10.1016/j.engstruct.2010.09.017

Reda, R.M., Sharaky, I.A., Ghanem, M., Seleem, M.H. and Sallam, HEM (2016). Flexural behavior of RC beams strengthened by NSM GFRP bars having different end conditions, Composite Structures, 147:131-142.

Sallam, H.E.M., Saba, A.M., Shaheen, H.H. and Abdel-Raouf, H. (2004). Prevention of peeling failure in plated beams" J. Advanced Concrete Technology, JCl, Vol. 2, No. 3, pp 419-429.

Shabana, S., Sharaky, I. A., Khalil, A., Hadad, H. S. and Arafa, E. M. (2018). Flexural Response Analysis of Passive and Active Near -Surface Mounted Joints: Experimental and Finite Element Analysis, Materials and Structures, 51:107.

Sharaky, I.A., Torres, Baena,L. M. and Miàs, C. (2013). An experimental study of different factors affecting the bond of NSM FRP bars in concrete, Composite Structures; 99:350-65.

Sharaky, I.A., Torres L., Comas, J. and Barris, C. (2014). Flexural response of reinforced concrete(RC) beams strengthened with near surface mounted (NSM) fibre reinforced polymer (FRP) bars, Composite Structures; 109:8-22.

Sharaky, I.A., Torres L. and Sallam, HEM (2015). Experimental and analytical investigation into the flexural performance of RC beams with partially and fully bonded NSM FRP bars/strips, Composite Structures; Vol. 122, pp: 113-126.

Sharaky, I.A., Reda R.M., Ghanem, M., Seleem, M.H. and Sallam, HEM (2017). Experimental and numerical study of RC beams strengthened with bottom and side NSM GFRP bars having different end conditions, Construction and Building Materials, Vol. 149, pp: 882-903.

Sharaky, I.A., Baena M, M, Barris C, Sallam, H.E.M., Torres, L.(2018). Effect of axial stiffness of NSM FRP reinforcement and concrete cover confinement on flexural behaviour of strengthened RC beams: Experimental and numerical study, Engineering Structures, Vol. 173, pp: 987-1001.

Sharaky, I.A., Selmy, S.A., El-Attar, M. and Sallam HEM (2020). The Influence of interaction between NSM and internal reinforcements on the structural behavior of upgrading RC Beams, Composite Structures, Vol. 234, 111751.

Soliman, S.M., E. El-Salakawy and B. Benmokrane (2010). Flexural behaviour of concrete beams strengthened with near surface mounted fibre reinforced polymer bars, Canadian Journal of Civil Engineering, 37(10): pp: 1371-1382. http://dx.doi.org/10.1139/L10-077

Tang, W.C., Balendran, R.V., Nadeem, A. and Leung, H.Y. (2006). Flexural strengthening of reinforced lightweight polystyrene aggregate concrete beams with near surface mounted GFRP bars, Building and Environment, 41(10):1381-1393.

Zhou, Y., Gou, Zhang, F., Zhang, S., and Wang, D. (2013). Reinforced Concrete Beams Strengthened with Carbon fiber reinforced polymer by Friction Hybrid Bond Technique: Experimental Investigation, Materials \& Design, 50:130-139. 